\title{
Coulisses
}

Revue de théâtre

5 | Hiver 1992

Varia

\section{Les Enfants Tanner, Mamie Ouate en Papoâsie}

Deux mises en scène de Joël Jouanneau

Lucile Garbagnati

\section{OpenEdition}

Journals

Édition électronique

URL : http://journals.openedition.org/coulisses/1714

DOI : 10.4000/coulisses. 1714

ISSN : 2546-9460

Éditeur

Presses universitaires de Franche-Comté

\section{Édition imprimée}

Date de publication : 1 janvier 1992

Pagination : 19-21

ISSN : 1150-594X

\section{Référence électronique}

Lucile Garbagnati, "Les Enfants Tanner, Mamie Ouate en Papoâsie », Coulisses [En ligne], 5 | Hiver 1992, mis en ligne le 04 juillet 2017, consulté le 22 octobre 2019. URL : http://journals.openedition.org/ coulisses/1714 ; DOI : 10.4000/coulisses.1714

Ce document a été généré automatiquement le 22 octobre 2019

Coulisses 


\section{Les Enfants Tanner, Mamie Ouate en Papoâsie}

Deux mises en scène de Joël Jouanneau

Lucile Garbagnati

«Un poète qui n'aime pas la vie est perdu. »

R. Walser.

1 Hasard ou concertation préalable, deux spectacles mis en scène par Joël Jouanneau ont été programmés à dix jours d'intervalle par le Centre Dramatique National et l'Espace Besançon-Planoise, permettant au public bisontin d'apprécier le travail d'un metteur en scène à la renommée flatteuse.

2 Les Enfants Tanner, adaptation du roman de Robert Walser en collaboration avec le traducteur Jean Launay, raconte les errances de Simon, le plus jeune des cinq enfants Tanner, et à travers elles l'histoire de sa famille; Mamie Ouate en Papoâsie, " comédie insulaire » de Joël Jouanneau lui même et de sa sœur Marie-Claire Le Pavec, narre la recherche du dernier spécimen du papillon Virginia sur l'île Blupblup en Papoâsie, pour un double public consciemment ciblé : celui des vingt ans pour l'un, celui des enfants pour l'autre. Or, dans des salles combles, le «tout public", toutes générations confondues, de trois à quatre-vingts ans et plus, ont vibré à l'expression du Désir, de son propre désir, en étant toute attention aux «contes» que "l'équipe de J. Jouanneau » lui donnaient à voir et à entendre.

3 Les Enfants Tanner, pareil à La Petite Marchande d'allumettes de C. Andersen, est un conte, rythmé par les saisons, qui se conclut sur un paysage de carte postale hivernale avec silhouettes se découpant sur fond de chalet, colline, sapins enneigés. Mamie Ouate en Papoâsie, rappelle le merveilleux exotique qui court de La Tempête à Vendredi ou les limbes du Pacifique en passant par Robinson Crusoë. Lieux de nulle part, où, dans une nature autre se déroulent les aventures les plus improbables et se nouent les relations à la fois les plus cruelles et les plus tendres.

4 Un décor de rêverie et de féerie. Les toiles peintes par Jacques Gabel pour Les enfants Tanner se métamorphosent au gré des éclairages, de l'errance de Simon, de l'imagination du spectateur en saisons et châteaux, plaines et montagnes magiques. 
L'île Blupblup, conçue par le même plasticien, c'est à la fois l'intérieur de la gueule, la tête et la queue d'un énorme poisson pareil à celui de Jonas ou de Pinocchio. La transformation des rideaux transparents, brume ou nuit étoilée, selon la lumière, crée avec l'irréel l'émerveillement.

5 Solo d'alto, chant choral pour Simon, partition orchestrale enregistrée pour Mamie Ouate, la musique est omniprésente. Elle prolonge l'émotion, évoque ce que ne peuvent dire ni les mots ni les attitudes, elle donne un contrepoint ironique au paroxysme. Elle participe de l'enchantement.

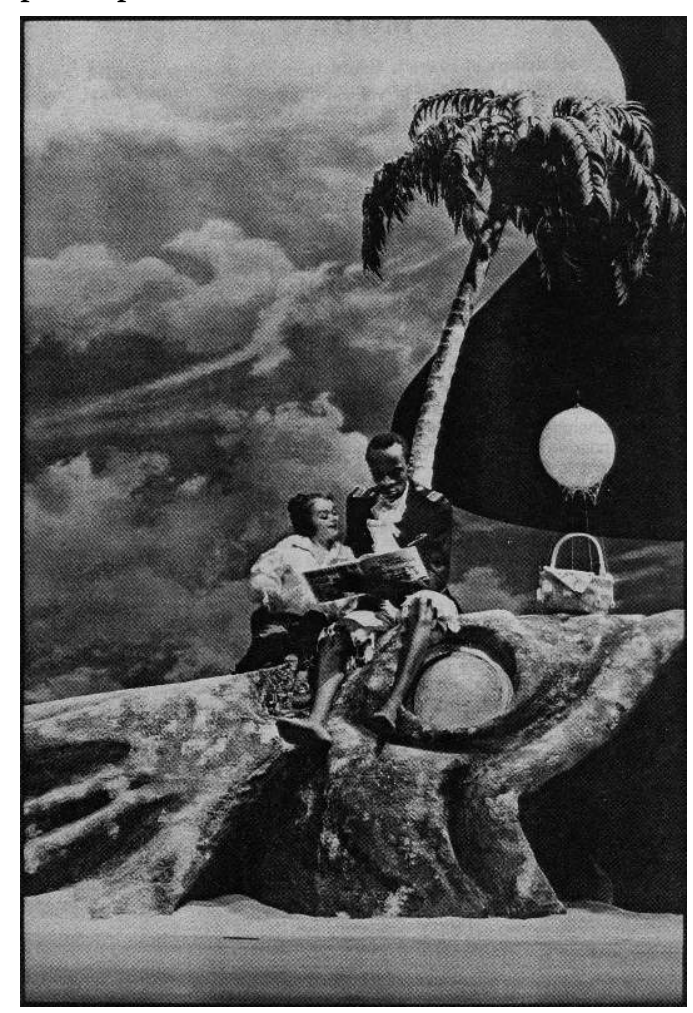

Mamie Ouate en Papoâsie.

Photo Brigitte Enguerrand, Paris.

Dans une telle atmosphère tout est "possible ", pour reprendre un mot, une notion chère à $\mathrm{R}$. Walser. Il devient normal qu' « un panier à provision descende très lentement soutenu par un petit parachute... avec champagne et foie gras» (p. 24) au moment même où Mamie Ouate commence à cuire avant d'être dévorée par son ami Kadouma mourant d'inanition.

7 Les personnages sont d'ici et d'ailleurs. Leurs dialogues, grâce à la traduction aérienne de Jean Launay et à la simplicité enfantine de J. Jouanneau et M.-C. Le Pavec, résonnent en échos dans la conscience des spectateurs portés par la voix et la diction musicale des acteurs.

8 Le dépouillement, la justesse de leur jeu font que chaque détail suscite l'attention. Les mains de Philippe Demarle, par exemple, indiquent presque à elles seules le parcours de Simon. L'expression du visage de Mireille Mossé donne à voir la gamme des émotions provoquées par le discours de Kadouma. 
9 Pause, moments d'écoute. Écoute mutuelle des personnages, du metteur en scène et de ses acteurs, de la scène et de la salle, des individus entre eux, on peut entendre la voix du silence de Walser et de Jouanneau.

10 Recherche d'un emploi hypothétique ou d'un papillon rare, errance physique qui déclenche la compassion et sa contre-note humoristique, quête initiatique dont la signification ultime est glissée à l'oreille du spectateur avec l'Oratorio de Brahms ou emportée sur un feuillet.

11 Je me souviens

d'avoir vu

Mamie Ouate en Papoâsie

Je me souviens

que c'était avec :

Je me souviens que :

" il y a dans ma tête plus d'énergie que dans une bombe nucléaire »

\section{BIBLIOGRAPHIE}

Les Enfants Tanner, Robert Walser, traduction Jean Launay, Gallimard.

Robert Walser, Dossier Pro Helvetia, L'âge d'homme.

Mamie Ouate en Papoâsie, Joël Jouanneau, Marie-Claire Le Pavec, Actes Sud-Papiers. 